02

\title{
Оптические характеристики пленок титаната стронция, полученных золь-гель методом
}

\author{
() Н.И. Стаськов ${ }^{1}$, А.Б. Сотский ${ }^{1}$, Л.И. Сотская ${ }^{2}$, И.В. Ивашкевич ${ }^{1}$, А.И. Кулак ${ }^{3}$, \\ Н.В. Гапоненко ${ }^{4,5}$, М.В. Руденко ${ }^{4}$, А.Н. Петлицкий ${ }^{6}$ \\ ${ }^{1}$ Могилевский государственный университет имени А.А. Кулешова, \\ 212022 Могилев, Беларусь \\ ${ }^{2}$ Белорусско-Российский университет, \\ 212000 Могилев, Беларусь \\ ${ }^{3}$ Институт общей и неорганической химии НАН Беларуси, \\ 220076 Минск, Беларусь \\ ${ }^{4}$ Белорусский государственный университет информатики и радиоэлектроники, \\ 220000 Минск, Беларусь \\ ${ }^{5}$ Национальный исследовательский ядерный университет „МИФИ“, \\ 115409 Москва, Россия \\ ${ }^{6}$ НТЦ БМС „Интеграл“, \\ 220108 Минск, Беларусь \\ e-mail: ni_staskov@mail.ru
}

Поступила в редакцию 06.03.2018 г.

В окончательной редакции 30.06.2018 г.

По данным многоугловой спектрофотометрии и спектроэллипсометрии в УФ и видимой областях рассчитаны спектры показателей преломления, поглощения и ширины запрещенной зоны однослойной и пятислойных пленок титаната стронция, полученных золь-гель методом. Послойное осаждение золя на кварцевые подложки от одного до пяти слоев приводит к увеличению пористости пленок от 4 до $33 \%$. Это вызывает уменьшение показателей преломления в средней части видимого спектра от 2.33 до 1.87 , приводящее к уменьшению отражательной способности и увеличению пропускательной способности или „прозрачности“ пятислойных пленок. При увеличении температуры прогрева таких пленок от 500 до $750^{\circ} \mathrm{C}$ максимум полосы поглощения смещается от 239 к $253 \mathrm{~nm}$, а оптическая ширина запрещенной зоны уменьшается от 4.63 до $4.20 \mathrm{eV}$. Максимум полосы поглощения однослойной пленки приходится на длину волны $252 \mathrm{~nm}$, а ее оптическая ширина запрещенной зоны $3.96 \mathrm{eV}$.

DOI: $10.21883 /$ OS.2018.10.46697.69-18

\section{Введение}

Титанат стронция $\mathrm{SrTiO}_{3}$ - широкозонный оксидный полупроводник перовскитной структуры, характеризующийся уникальным сочетанием высокой диэлектрической проницаемости и оптической прозрачности в видимой области, химической и композиционной стабильности и ряда других физических свойств, которые определяют его перспективность для опто- и микроэлектроники. Пленки на основе $\mathrm{SrTiO}_{3}$ представляют интерес для создания структур МДП и конденсаторов динамической оперативной памяти DRAM, монолитных микроволновых интегральных схем MMICs и датчиков ИК излучения [1]. Обратимый переход $\mathrm{SrTiO}_{3}$ из высокоомного состояния в низкоомное под действием УФ и видимого излучения открывает перспективу применения этого материала в качестве мемристоров - элементов энергонезависимой памяти [2-6]. Интенсивная фото-, катодо- и радиолюминесценция обнаружена у пленок $\mathrm{SrTiO}_{3}$, легированных лантаноидами $[7,8]$.

Пленки $\mathrm{SrTiO}_{3}$ получают как физическими (магнетронным, импульсным лазерным осаждением), так и химическими методами, среди которых наиболее рас- пространенной является золь-гель технология [9-15]. Этим методом при относительно невысоких температурах можно получать качественные пленки, имеющие высокую степень кристалличности и соответствующие стехиометрии $\mathrm{SrTiO}_{3}[16]$. Для достижения необходимой толщины пленок применяют последовательное многослойное осаждение, что, однако, приводит к повышению их пористости и изменению оптических свойств [17]. Кроме того, повышение температуры термообработки от 500 до $750^{\circ} \mathrm{C}$ приводит к изменению их толщины и уменьшению ширины запрещенной зоны $E_{g}$. Известно, что значение $E_{g}$ для прямых оптических переходов в кристаллических пленках $\mathrm{SrTiO}_{3}$ варьирует от 3.43 до $3.62 \mathrm{eV}$ [18], в аморфно-кристаллических — от 3.68 до $3.94 \mathrm{eV}$ [19], а в аморфных пленках увеличивается до $4.07 \mathrm{eV}[20]$.

В настоящее время для оценки ширины запрещенной зоны полупроводниковых пленок используются методики [17,21-26], основанные на следующих предположениях:

- в области полосы поглощения пленки подложка не поглощает свет (ее показатель поглощения $k_{s}=0$ ); 
- коэффициент поглощения $\alpha_{f}(\lambda)$ пленки, зависящий от ее показателя поглощения $k_{f}(\lambda)[27]$ и длины волны $\lambda$ как

$$
\alpha_{f}(\lambda)=\frac{4 \pi k_{f}(\lambda)}{\lambda},
$$

можно определить на основании приближенных формул, в которых учитывают потери света только из-за поглощения (закон Бугера) [17,21],

$$
\alpha_{f}(\lambda)=\frac{1}{h_{f}} \ln \frac{1}{T_{t}(\lambda)}
$$

поглощения и однократного отражения [22,23],

$$
\alpha_{f}(\lambda)=\frac{1}{h_{f}} \ln \frac{1-R_{t}(\lambda)}{T_{t}(\lambda)},
$$

поглощения и двукратного отражения [24],

$$
\alpha_{f}(\lambda)=\frac{1}{h_{f}} \ln \frac{\left[1-R_{t}(\lambda)\right]^{2}}{T_{t}(\lambda)} .
$$

Расчет коэффициента поглощения в области края полосы собственного поглощения полупроводников выполняют [25] и по более сложной формуле:

$$
\alpha_{f}(\lambda)=\frac{1}{h_{f}} \ln \frac{\left[1-R_{t}(\lambda)\right]^{2}}{2 T_{t}(\lambda)}+\sqrt{\left(\left[R_{t}(\lambda)\right]^{2}+\frac{\left[1-R_{t}(\lambda)\right]^{4}}{\left.4\left[T_{t}(\lambda)\right]^{2}\right)}\right.} .
$$

В формулах (2)-(5) параметр $h_{f}-$ измеренная в сантиметрах толщина пленки, $T_{t}(\lambda)$ и $R_{t}(\lambda)-$ измеренные пропускательная и отражательная способности пленки на подложке при нормальном $(\varphi=0)$ падении неполяризованного света на образец. После расчета спектра коэффициента поглощения появляется возможность на основании экстраполяции Тауца [28],

$$
\left[\alpha_{f}(\lambda) E\right]^{2}=B\left(E-E_{g}\right)
$$

определить ширину запрещенной энергетической зоны $\mathrm{SrTiO}_{3}$. В формуле (6) $B$ - постоянная, $E=1240 \lambda^{-1}-$ энергия фотона в электронвольтах (длина волны $\lambda$ берется в нанометрах). Пересечение линейного участка зависимости $\left[\alpha_{f}(\lambda) E\right]^{2}$ с осью $E$ дает оценку $E_{g}$.

Формулы (2)-(5) получены для толстых слоев в пренебрежении интерференцией света в них.Для того чтобы исключить в (2) влияние отраженного света для тонкой пленки при наличии интерференции, обратимся к закону сохранения энергии $T_{t}(\lambda)+R_{t}(\lambda)+A_{t}(\lambda)=1$, где $A_{t}(\lambda)$ - поглощательная способность структуры пленка-подложка. В области отсутствия поглощения света подложкой $k_{s}(\lambda)=0$ на основании закона Бугера можно допустить $A_{t}(\lambda)=h_{f} \alpha_{f}(\lambda)$. Тогда вне полосы собственного поглощения пленки, где $h_{f} \alpha_{f}(\lambda) \ll 1$, имеем $T_{t}(\lambda)+R_{t}(\lambda)=\exp \left[h_{f} \alpha_{f}(\lambda)\right]$. В этом приближении

$$
\alpha_{f}(\lambda)=\frac{1}{h_{f}} \ln \frac{1}{T_{t}(\lambda)+R_{t}(\lambda)} .
$$

В отличие от выражения (1), где предполагается, что показатель поглощения пленки $k_{f}(\lambda)$ определяется из строгого решения обратной задачи спектрофотометрии, приближения (2)-(5), (7) содержат неизвестный параметр - толщину пленки. Для определения $h_{f}$ используют методы поверхностной профилометрии [22,23] и спектральной эллипсометрии [26]. Все эти методы характеризуются разной точностью определения величины $h_{f}$. Для непоглощающих сред $\alpha_{s}(\lambda)=0, k_{f}(\lambda)=0$, $T_{t}(\lambda)+R_{t}(\lambda)=1$, и из (3), (7) имеем $\alpha_{f}(\lambda)=0$. Однако соотношения (2), (4), (5) дают $\alpha_{f}(\lambda) \neq 0$, что ставит под сомнение применимость выражений (2), (4), (5) для определения показателя поглощения пленок $\mathrm{SrTiO}_{3}$.

В настоящей работе для исследования причин изменения оптической прозрачности и ширины запрещенной зоны $\mathrm{SrTiO}_{3}$ при последовательном многослойном осаждении золя на кварцевые пластины с помощью разработанного алгоритма решены обратные задачи многоугловой спектрофотометрии для однородных пленок на плоскопараллельных кварцевых подложках конечной толщины. Определены толщины, спектры показателей преломления $n_{f}(\lambda)$ и поглощения $k_{f}(\lambda)$ однослойной и пятислойных пленок. На этой основе проанализированы возможности использования известных приближенных формул для оценок ширины запрещенной зоны и показателя поглощения.

Для расчета спектров $T_{t}(\lambda)$ и $R_{t}(\lambda)$ однородной пленки на плоскопараллельной подложке конечной толщины (прямая задача спектрофотометрии) мы использовали решение электродинамической задачи о пропускании и отражении от данной структуры частично когерентного света. Разработаны две компьютерные программы. В первой из них гауссову аппаратную функцию монохроматора интегрировали в свертке с когерентными отражательными и пропускательными способностями структуры. Во второй программе функции $T_{t}(\lambda)$ и $R_{t}(\lambda)$ рассчитывались суммированием лучевых рядов. Первая программа служила для оценки границ применимости второй, менее точной, но с существенно меньшим объемом вычислений. Алгоритм последней был положен в основу построения целевых функций для численного отыскания спектров $n_{s}(\lambda)$ и $k_{s}(\lambda)$ подложки с последующим восстановлением методом наименьших квадратов функций $n_{f}(\lambda), k_{f}(\lambda)$ и толщины пленки $h_{f}$. Разработанные программы [29] позволяют учесть конечность толщины подложки, поглощение света во всей структуре и увеличение длины пути света в пленке и подложке при наклонном падении. При этом какие-либо ограничения на толщину пленки и подложки не накладываются. Для численного определения пяти основных характеристик $h_{f}, n_{f}(\lambda), k_{f}(\lambda), n_{s}(\lambda)$ и $k_{s}(\lambda)$ (обратная задача спектрофотометрии) надо вначале измерить спектры $T_{s}(\lambda)$ и $R_{s}(\lambda)$ подложки без пленки, а затем спектры $T_{t}(\lambda)$ и $R_{t}(\lambda)$ подложки с пленкой. Контроль функций $n_{s}(\lambda)$ и $k_{s}(\lambda)$ необходим ввиду их заметного отклонения от известных из литературы дисперсионных таблиц в условиях реального эксперимента. 


\section{Эксперимент}

Для получения пленок титаната стронция использовали золь, приготовленный смешиванием растворов ацетата стронция в уксусной кислоте и тетраизопропоксида титана $\mathrm{Ti}\left(\mathrm{OCH}\left(\mathrm{CH}_{3}\right)_{2}\right)_{4}$ в монометиловом эфире этиленгликоля в присутствии ацетона в качестве стабилизатоpa [6]. Пленки наносили на кварцевые подложки центрифугированием со скоростью вращения 2700 об/мин. Каждый слой $\mathrm{SrTiO}_{3}$ высушивали и подвергали предварительной термообработке при $200^{\circ} \mathrm{C}$. После нанесения пяти слоев осуществляли заключительную термообработку структуры при температурах $500-750^{\circ} \mathrm{C}$ на воздухе в течение $60 \mathrm{~min}$.

Толщина кварцевой подложки $h_{s}=3.50 \mathrm{~mm}$ измерена на горизонтальном оптиметре ИКГ 1. Спектры отражения и пропускания подложки $T_{s}(\lambda), R_{s}(\lambda)$ и подложки с однослойной пленкой $T_{t}(\lambda), R_{t}(\lambda)$ для света ТЕ- и ТМполяризации (векторы электрического поля света ТМ- и TE- поляризаций лежат в плоскости падения и перпендикулярно ей соответственно) регистрировали при углах падения $8^{\circ}, 24^{\circ}$ и $40^{\circ}$ на спектрофотометре Photon RT в спектральной области от 250 до $700 \mathrm{~nm}$. Спектры $T_{t}(\lambda)$ пятислойных пленок на кварцевой подложке получали на спектрофотометре Cary-500 в диапазоне от 200 до $700 \mathrm{~nm}$ при $\varphi=0$ [17]. Спектры эллипсометрических углов подложки $\psi_{s}(\lambda)$ и $\Delta_{s}(\lambda)$ и подложки с однослойной пленкой $\psi_{t}(\lambda)$ и $\Delta_{t}(\lambda)$ измеряли соответственно при углах падения $60^{\circ}$ и $65^{\circ}$ на спектральном эллипсометре Horiba UVISEL в области $200-700 \mathrm{~nm}$.

\section{Результаты}

На рис. 1 приведены спектры пропускательных (a) и отражательных $(b)$ способностей трех исследуемых пленок на кварцевых подложках. Спектры $n_{s}(\lambda)$ и $k_{s}(\lambda)$ подложки восстанавливали по спектрам $T_{s}(\lambda)$ и $R_{s}(\lambda)$, измеренным при трех вышеуказанных углах падения и двух поляризациях света. На рис. 2 приведены спектры показателей преломления $(a)$ и поглощения $(b)$ трех исследуемых пленок. При определении $n_{f}(\lambda)$ и $k_{f}(\lambda)$ (кривые 1) однослойной пленки использовали модель однородная пленка-подложка, в которой обрабатывались восемь спектров $T_{t}(\lambda)$ и $R_{t}(\lambda)$, измеренные с использованием ТЕ- и ТМ-поляризации света при углах падения $8^{\circ}$ и $24^{\circ}$. Рассчитанная в этом случае толщина пленки оказалась равной $33.6 \mathrm{~nm}$. Расчет толщин и оптических функций $n_{f}(\lambda)$ и $k_{f}(\lambda)$ двух пятислойных пленок осуществили по формулам для $T_{t}(\lambda)$ из работы [30], в которые для $\varphi=0$ подставляли спектры 2 и3 (рис. 1, $a$ ). Толщины пятислойных термически обработанных при 500 и $750^{\circ} \mathrm{C}$ пленок $\mathrm{SrTiO}_{3}$ оказались соответственно равными 186 и $194 \mathrm{~nm}$. Полученное из строгих расчетов значение толщины пленки, обработанной при $750^{\circ} \mathrm{C}$, близко к определенному методом электронной микроскопии $\sim 190 \mathrm{~nm}$ [17]. Рассчитанные спектры по- казателей преломления и поглощения двух термически обработанных пленок представлены кривыми 2 и 3 на рис. 2. Решения обратной задачи спектрофотометрии для пятислойных пленок позволили по формулам для $R_{t}(\lambda)$ из работы [30] при $\varphi=0$ рассчитать их отражательные способности (кривые 2 и 3 на рис. $1, b$ ).

Одним из критериев корректности численного решения вышерассмотренной обратной оптической задачи является соответствие решений, полученных разными методами, например, спектрофотометрии и спектральной эллипсометрии. С помощью программного обеспечения DeltaPsi2 к эллипсометру Horiba UVISEL по измеренным спектрам $\psi_{s}(\lambda), \Delta_{s}(\lambda)$ и $\psi_{t}(\lambda), \Delta_{t}(\lambda)$ мы рассчитали параметры подложки и однослойной пленки $\mathrm{SrTiO}_{3}$. Дисперсионная зависимость показателей преломления и поглощения $\mathrm{SrTiO}_{3}$ от энергии фотона $E$ в программном обеспечении DeltaPsi2 определялась по формулам [31]

$$
\begin{aligned}
& n_{f}(E)=n_{\infty}+\left[B\left(E-E_{j}\right)+C\right]\left[\left(E-E_{j}\right)^{2}+\Gamma_{j}^{2}\right]^{-1}, \\
& k_{f}(E)= \begin{cases}\left(f_{j}\left(E-E_{g}\right)^{2}\left[\left(E-E_{j}\right)^{2}+\Gamma_{j}^{2}\right]^{-1},\right. & E>E_{g} \\
0, & E<E_{g},\end{cases}
\end{aligned}
$$

где $\quad B=f_{j} \Gamma_{j}^{-1}\left[\Gamma_{j}^{2}-\left(E_{j}-E_{g}\right)^{2}\right], \quad C=2 f_{j} \Gamma_{j}\left(E_{j}-E_{g}\right)$, $n_{\infty}$ - показатель преломления, соответствующий нулевой энергии фотона, $E_{j}$ - энергия фотона, на которую приходится максимум полосы поглощения, $f_{j}-$ упругая постоянная осциллятора, $\Gamma_{j}-$ полуширина полосы поглощения, $E_{g}$ - энергия фотона, на которую приходится край полосы поглощения. Наименьшая невязка рассчитанных и измеренных спектров $\psi_{t}(\lambda)$ и $\Delta_{t}(\lambda)$ достигнута для модели шероховатый слойпленка-подложка. Толщина шероховатого слоя составила $(4.1 \pm 0.4) \mathrm{nm}$. Слой моделировался эффективной средой Бруггемана [32], которая включала 50\% воздуха и 50\% $\mathrm{SrTiO}_{3}$. Параметры вышеприведенных дисперсионных формул (8) и (9) для материала пленки оказались равными: $n_{\infty}=2.00 \pm 0.04, \quad E_{g}=(3.1 \pm 0.1) \mathrm{eV}, f_{j}=$ $=0.41 \pm 0.02, E_{j}=(4.39 \pm 0.05) \mathrm{eV}, \Gamma_{j}=(0.84 \pm 0.05) \mathrm{eV}$. Толщина однослойной пленки без шероховатого слоя $(31.4 \pm 0.6) \mathrm{nm}$, что удовлетворительно подтверждает величину, определенную выше методом спектрофотометрии. На рис. 2 приведены рассчитанные по формулам (8) и (9) соответствующие спектры показателей преломления и поглощения (кривые 4) этой пленки. В видимой области, где $E<E_{g}$, спектры $n_{f}(\lambda)$ и $k_{f}(\lambda)$, рассчитанные по данным двух оптических методов, находятся в удовлетворительном соответствии (кривые 1 и 4).

В работе [33] для описания оптических свойств тонкой кристаллической эпитаксиальной пленки $\mathrm{SrTiO}_{3}$ в видимой области спектра использовали дисперсионную модель Лорентца:

$$
n(\lambda)-i k(\lambda)=\sqrt{\varepsilon_{\infty}+\frac{A}{E_{g}^{2}-E^{2}+i \Gamma_{0} E}} .
$$



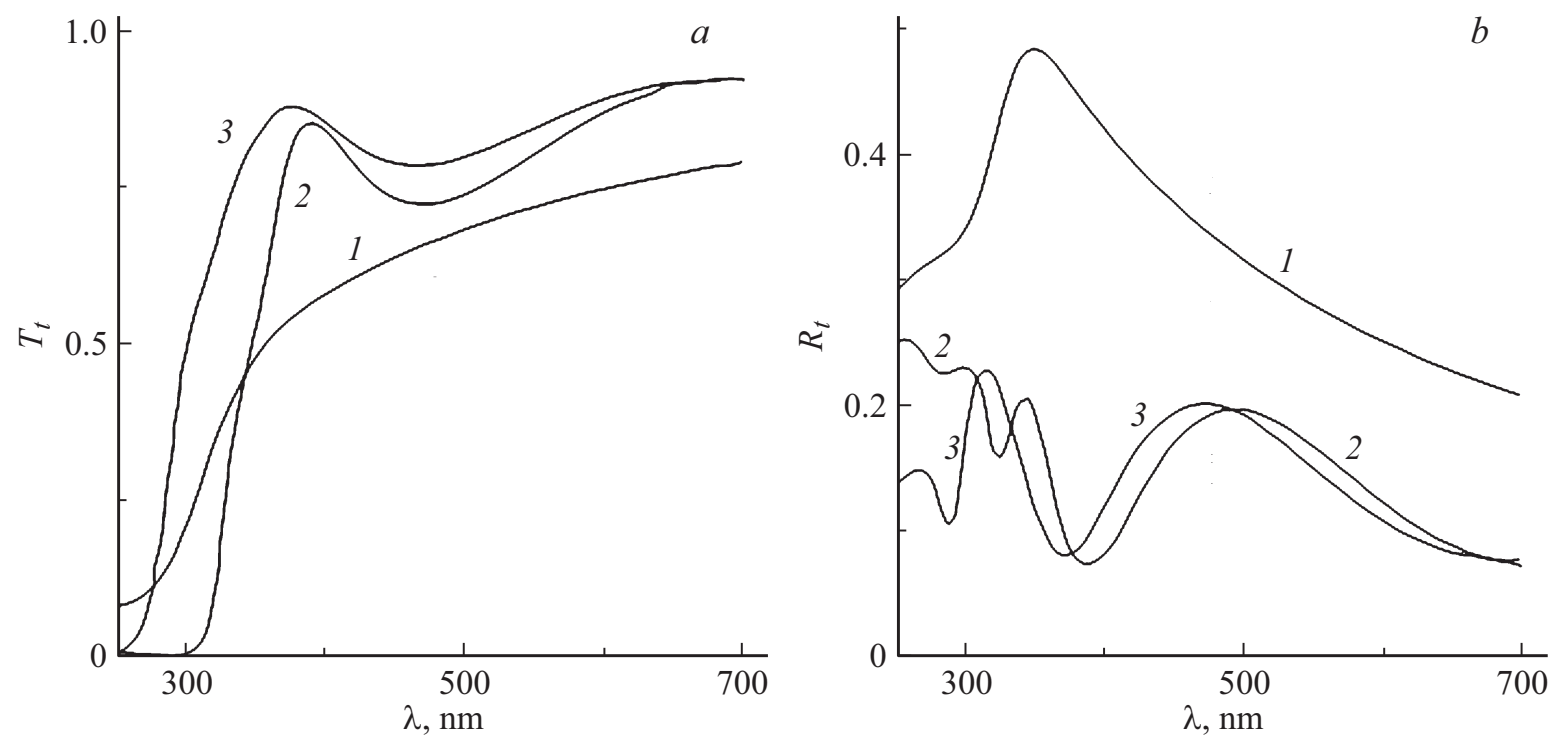

Рис. 1. Спектры пропускания $(a)$ и отражения $(b)$ однослойной $(1)$ и пятислойных, термически обработанных при 750 (2) и $500^{\circ} \mathrm{C}(3)$ пленок $\mathrm{SrTiO}_{3}$ на кварцевых подложках.
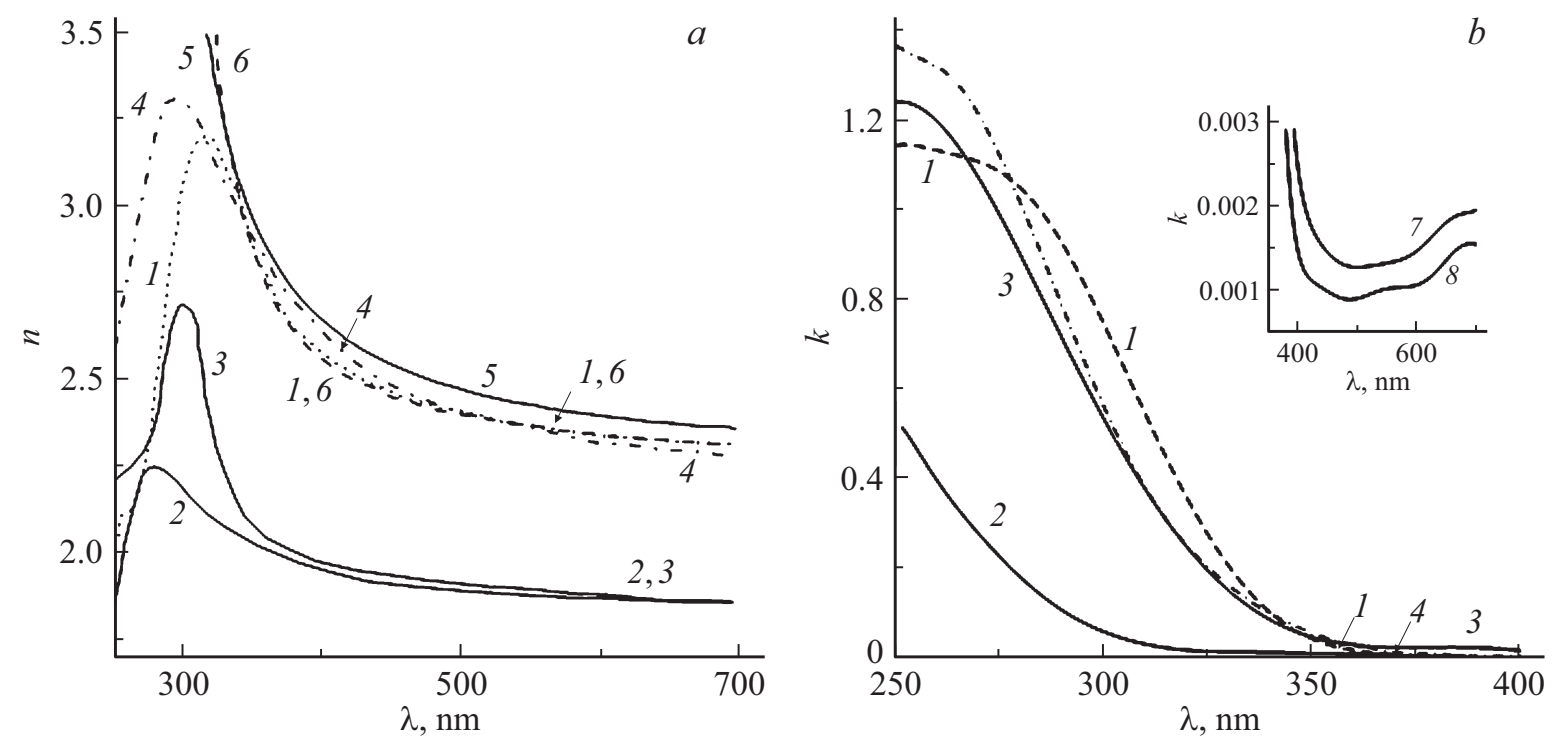

Рис. 2. Спектры показателей преломления $(a)$ и поглощения $(b)$ пленок $\mathrm{SrTiO}_{3}$ : однослойная $(1,4$, 7, 8); пятислойные, обработанные при 500 (2) и $750^{\circ} \mathrm{C}(3)$; модельная (5); эпитаксиальная (6) [30].

Кривая 5 на рис. 2, $a$ построена по параметрам $\varepsilon_{\infty}=3.077, E_{g}=4.466 \mathrm{eV}, A=41.874 \mathrm{eV}^{2}, \Gamma_{0}=0$, приведенным в работе [33]. Мы численно рассчитали параметры модели Лорентца $\varepsilon_{\infty}=3.98 \pm 0.02$, $E_{g}=(4.14 \pm 0.06) \mathrm{eV}, A=(19.4 \pm 0.1) \mathrm{eV}^{2}, \Gamma_{0}=0$ для интерполяции в области от 400 до $700 \mathrm{~nm}$ функцией (10) (кривая 6, рис. 2,a) экспериментального показателя преломления (кривая 1) однослойной пленки $\mathrm{SrTiO}_{3}$. Обратим внимание, во-первых, на равенство нулю параметров $\Gamma_{0}$ в $(10)$ и $k(E)$ в $(9)$. Это является следствием того, что исследуемая однослойная пленка $\mathrm{SrTiO}_{3}$ практически не поглощает видимый свет. Во-вторых, для модели (10) значение параметра $n_{\infty}=1.994$ практически совпадает со значением этого параметра, рассчитанного для модели (8). Расположение кривых 1-4 и 5 на рис. $2, a$ в видимой области спектра можно объяснить тем, что плотность эпитаксиальной пленки больше плотности пленок, полученных золь-гель методом.

В приближении модели эффективной среды Бруггемана определим процентное содержание воздуха и $\mathrm{SrTiO}_{3}$ в исследуемых пленках. Для этого допустим, что эпитаксиальная пленка не содержит воздух. Так как в видимой области показатели поглощения всех исследованных пленок близки к нулю, то по их эффективным показателям преломления (кривые $1-3$, рис. $2, a$ ) находим, что в однослойной пленке содержится око- 


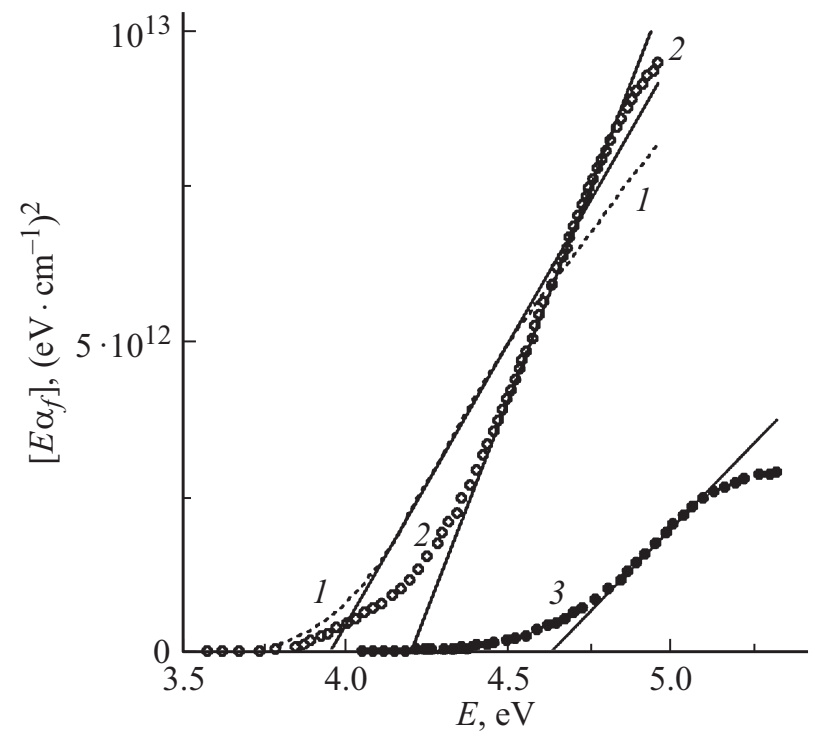

Рис. 3. Функции Тауца для однослойной (1), пятислойных, термически обработанных при 750 (2) и $500^{\circ} \mathrm{C}$ (3) пленок $\mathrm{SrTiO}_{3}$.

Ширина запрещенной зоны однослойной пленки $\mathrm{SrTiO}_{3}$

\begin{tabular}{c|c|c|c|c|c}
\hline$E_{g}, \mathrm{eV}$ & 3.89 & 3.98 & 4.08 & 4.08 & 3.96 \\
\hline Формула & $(2)$ & $(3)$ & $(4)$ & $(5)$ & $(1)$
\end{tabular}

ло $4 \%$ воздуха $\left(96 \% \mathrm{SrTiO}_{3}\right)$. В пятислойных пленках, полученных при разных температурах термообработки, содержится около $33 \%$ воздуха и $67 \% \mathrm{SrTiO}_{3}$.

С увеличением температуры термообработки пятислойных пленок от 500 до $750^{\circ} \mathrm{C}$ максимумы полос поглощения и максимумы дисперсионной зависимости $n_{f}(\lambda)$ (кривые 2, 3 на рис. 2) увеличиваются и смещаются в длинноволновую область. Адекватно смещаются и края полос поглощения.

Для определения ширины запрещенной зоны трех исследуемых пленок $\mathrm{SrTiO}_{3}$ по показателям поглощения (кривые 1-3, рис. 2,b) на основании формулы (1) рассчитывали коэффициенты поглощения и по (6) построили функции Тауца (рис. 3). Из рис. 3 видно, что для однослойной пленки (кривая 1 ) $E_{g}=3.96 \mathrm{eV}$, а для пятислойных пленок, термически обработанных при температурах $750^{\circ} \mathrm{C}$ (кривая 2), $E_{g}=4.20 \mathrm{eV}$, и $500^{\circ} \mathrm{C}$ (кривая 3), $E_{g}=4.63 \mathrm{eV}$.

Проанализируем возможности использования для оценок ширины запрещенной зоны однослойной пленки титаната стронция известных приближенных формул (2)(5). При угле падения $8^{\circ}$ увеличением длины пути света в пленке и подложке можно пренебречь. Поэтому для расчета $\alpha_{f}(\lambda)$ однослойной пленки будем использовать $h_{f}=33.6 \mathrm{~nm}$. В таблице приведены величины $E_{g}$ (первая строчка таблицы), которые были рассчитаны графически на основании приближенных формул (2)-(5) (вторая строчка таблицы) по измеренным спектрам $T_{t}(\lambda)$ и $R_{t}(\lambda)$ (кривые 1, рис. 1).

Для однослойной пленки $\mathrm{SrTiO}_{3}$ формула (3) позволяет получить значение $E_{g}$ практически совпадающее с таковым, рассчитанным на основании выражения (1). Это можно объяснить тем, что в области полосы собственного поглощения $\mathrm{SrTiO}_{3} k_{f}(\lambda)$ велико и из-за этого свет проходит через пленку не более двух раз. Формула (2) позволяет оценить минимальное значение ширины запрещенной зоны, а формулы (4) и (5) - eе максимальное значение.

Решения обратных задач спектрофотометрии, приведенные на рис. $2, b$, показывают, что в области $380<\lambda<700 \mathrm{~nm}$ исследуемые пленки титаната стронция не поглощают свет $\left(k_{f}(\lambda)=0\right)$. Мы рассмотрели возможность определения $k_{f}(\lambda)$ однослойной пленки по спектрам коэффициентов поглощения, которые были рассчитаны в выделенной спектральной области по приближенным формулам (2)-(5), (7). Для этого из выражения (1) получили $k_{f}(\lambda)=\lambda \alpha_{f}(\lambda)(4 \pi)^{-1}$. Формула (2) приводит к завышенным значениям показателя поглощения $\left(k_{f}(\lambda)>0\right)$. Формулы (4), (5) на отдельных участках спектра приводят к отрицательным значениям $k_{f}(\lambda)$. В отличие от формулы (3) минимальные значения показателей поглощения можно получить с помощью формулы (7). Соответствующие спектры $k_{f}(\lambda)$ представлены кривыми 7 и 8 на вставке рис. $2, b$. В области полосы поглощения для оценки показателя поглощения можно использовать формулу (3).

Таким образом, послойное осаждение золя на кварцевые подложки от одного до пяти слоев приводит к увеличению пористости пленок титаната стронция от 4 до 33\%. Это вызывает уменьшение показателя преломления пленок в средней части видимого спектра от 2.33 до 1.87 (кривые 1-4 на рис. 2, $a$ ). Уменьшение показателя преломления пятислойных пленок в сравнении с показателем преломления однослойной пленки приводит соответственно к уменьшению их отражательной способности (кривые $1-3$, рис. $1, b$ ) и увеличению пропускательной способности (кривые 1-3, рис. 1,a). Прозрачность пленок $\mathrm{SrTiO}_{3}$ в видимой области спектра определяется дисперсией показателя преломления.

\section{Заключение}

Тонкие однослойные пленки $\mathrm{SrTiO}_{3}$, полученные зольгель методом, имеют малую пористость $(\approx 4 \%)$. Их полоса поглощения с максимумом $k(252 \mathrm{~nm})=1.148$ обусловлена прямозонными переходами электронов на экситонные уровни в запрещенной зоне. Пятислойные пленки имеют высокую пористость ( $\approx 33 \%)$. При увеличении температуры прогрева пятислойных пленок от 500 до $750^{\circ} \mathrm{C}$ полоса поглощения уширяется, а ее максимум увеличивается от $k(239 \mathrm{~nm})=0.603$ до $k(253 \mathrm{~nm})=1.237$ и смещается в длинноволновую об- 
ласть. Полосы находятся в области аномальной дисперсии показателей преломления.

С увеличением температуры термообработки пятислойных пленок увеличивается показатель преломления, соответствующий длине волны максимума полосы поглощения, от $n(239 \mathrm{~nm})=1.730$ до $n(253 \mathrm{~nm})=2.204$. Уменьшение показателя преломления многослойных пленок $(n=1.872)$ в сравнении с таковым для однослойной пленки $(n=2.331)$ в области отсутствия поглощения $(\lambda=632.8 \mathrm{~nm})$ приводит к увеличению их пропускательной способности или прозрачности.

Ширина запрещенной зоны, рассчитанная строго по спектру $k_{f}(\lambda)$ пленки, находится в пределах, которые задают известные приближенные формулы. Нижний предел $E_{g}$ можно оценить по формуле, которая не учитывает отражение света от структуры пленкаподложка. Верхний предел величины $E_{g}$ определяется формулами, которые дважды учитывают отражение света. В области полосы поглощения лучшее приближение $\left(\delta E_{g} / E_{g} \approx 1 \%\right)$ к спектру $\alpha_{f}(\lambda)$ тонкой пленки $\mathrm{SrTiO}_{3}$ дает эмпирическая формула (3), которая учитывает разовое отражение света от структуры пленка-подложка. При золь-гель наслоении пленок $\mathrm{SrTiO}_{3}$ ширина запрещенной зоны увеличивается от 3.96 до $4.63 \mathrm{eV}$.

Работа выполнена при поддержке Государственной программы научных исследований Республики Беларусь „Фотоника, опто- и микроэлектроника 1.3.03“ (2016-2017 гг.).

\section{Список литературы}

[1] Brebner J.L., Jandl S., Lépine Y. // Phys. Rev. B. 1981. V. 23. P. 3816.

[2] Pontes F.M., Lee E.J.H., Leite E.R.., Longo E., Varela J.A. // J. Mat. Science. 2000. V. 35. P. 4783.

[3] Amy F., Wan A., Kahn A., Walker F.J., McKee R.A. // J. Appl. Phys. 2004. V. 96. N 3. P. 1601.

[4] Sakyo Hirose, Akinori Nakayama, Hideaki Niimi, Keisuke Kageyama, Hiroshi Takagi // J. Appl. Phys. 2008. V. 104. P. 053712. doi 10.1063/1.2975316

[5] Tarun M.C., Selim F.A., McCluskey M.D. // Phys. Rev. Lett. 2013. V. 111. P. 187403.

[6] Сохраби Анараки Х., Гапоненко Н.В., Литвинов В.Г., Ермачихин А.В., Колос В.В., Петлицкий А.Н., Иванов В.А. // ФTT. 2015. T. 57. № 10. C. 1977.

[7] Gaponenko N.V., Kortov V.S., Rudenko M.V., Pustovarov V.A., Zvonarev S.V., Slesarev A.I., Molchan I.S., Thompson G.E., Khoroshko L.S., Prislopskii S.Ya. // J. Appl. Phys. 2012. V. 111. P. 103101.

[8] Podhorodecki A., Gaponenko N.V., Banski M., Rudenko M.V., Khoroshko L.S., Sieradzki A., Misiewicz J. // Opt. Mater. 2012. V. 34. N 9. P. 1570.

[9] Singha S.B., Sharma H.B. // Eur. Phys. J. Appl. Phys. 2009. V. 45. P. 30602.

[10] Hiibert T., Beck U., Kleinke H. // J. Non-Cryst. Solids. 1996. V. 196. P. 150.

[11] Fuentes S., Zarate R.A., Chavez E., Munoz P.,DlazDroguett D., Leyton P. // J. Mater. Sci. 2010. V. 45. P. 1448.
[12] Reji T., Dube D.C., Kamalasanan M.N., Subhas Chandra, Bhalla A.S. // J. Appl. Phys. 1997. V. 82. P. 4484.

[13] Reji T., Dube D.C. // Jpn. J. Appl. Phys. 2000. V. 39. P. 1771.

[14] Kamalasanan M.N., Deepak Kumar N., Subhas Chandra // J. Appl. Phys. 1993. V. 74. P. 679.

[15] Dinghua Bao, Xi Yao, Naoki Wakiya, Kazuo Shinozaki, Nobuyasu Mizutani // Appl. Phys. Lett. 2001. V. 79. P. 3767.

[16] Kosola A., Putkonen M., Johansson L.-S., Niinisto L. // Appl. Surf. Sci. 2003. V. 211. P. 102.

[17] Кулак А.И., Сохраби Анараки Х., Гапоненко Н.В., Хорошко Л.С., Холов П.А., Райченок Т.Ф. // ЖПС. 2017. Т. 84. № 1. C. 150.

[18] Du Y., Zhang M.-S., Wu J., Kang L., Yang S., Wu P., Yin Z. // Appl. Phys. A. 2003. V. 76. P. 1105.

[19] Roy D., Peng C.J., Krupanidhi S.B. // Appl. Phys. Lett. 1992. V. 60. N 3. P. 2478.

[20] Baba S., Numata K., Miyake S. // Sci. Technol. Adv. Mater. 2000. V. 1. P. 211.

[21] Уханов Ю.И. Оптические свойства полупроводников. М.: Наука, 1977. 368 с.

[22] Kim Y.H., Lee K.S., Lee T.S., Cheong B., Seong T.-Y., Kim W.M. // Appl. Surf. Science. 2009. V. 255. P. 7251.

[23] Lee S.H., Lee T.S., Lee K.S., Cheong B., Kim Y.D., Kim W.M. // J. Phys. D. 2008. V. 41. P. 095303.

[24] Новодворский О.А., Горбатенко Л.С., Панченко В.Я. // ФТП. 2009. Т. 43. № 4. С. 439.

[25] Edward D. Palik. Handbook of optical constants of solids. Academic Press, 1988. P. 230.

[26] Li Q.H., Zhu D., Liu W., Liu Y., Ma X.C. // Appl. Surf. Science. 2008. V. 254. P. 2922.

[27] Борн М., Воль $\varnothing$ Э. Основы оптики. М.: Наука, 1970. 856 с.

[28] Tauc J., Grigorovici R., Vancu A. // Phys. Stat. Sol. 1966. V. 15. P. 627.

[29] Сотский А.Б., Кривецкий К.Н., Федотко А.А., Дзен И.С., Парашков С.О., Стаськов Н.И., Сотская Л.И. // Материалы Всероссийской научной Интернет-конференции с международным участием „Спектрометрические методы анализа“. Казань, 26 сентября 2013. С. 103.

[30] Minkov D. // JOSA. A. 1991. V. 8. N 2. P. 306.

[31] Eunice S.M. Goh, Chen T.P., Sun C.Q., Liu Y.C. // J. Appl. Phys. 2010. V. 107. P. 024305.

[32] Головань Л.А., Тимоченко В.Ю., Кашкаров П.К. // УФН. 2007. T. 177. № 6. C. 619.

[33] Stefan Zollner, Demkov A.A., Liu R., Fejes P.L., Gregory R.B., Prasad Alluri, Curless J.A., Yu Z., Ramdani J., Droopad R., Tiwald T.E., Hilfiker J.N., John A. Woollam // J. Vac. Sci. Technol. B. 2000. V. 18. N 4. P. 2242. 